NEWS

\title{
Data show extent of sexism in physics
}

Women are poorly represented in physics, making up just $10 \%$ of faculty in the United States, for example, but the reasons for this have proved contentious. Now a particle physicist claims to have hard data showing institutional sexism at an experiment at one of America's highestprofile physics labs.

Sherry Towers claims that female postdocs worked significantly harder than their male peers but were awarded one-third as many conference presentations proportionally. "There was this shocking difference," says Towers, who now studies statistics at Purdue University in West Lafayette, Indiana. "Particle physics really hasn't moved forward in 30 years."

Towers used data from publicly available work records to chart the careers of 57 postdoctoral researchers, including nine women, who worked on the 'DZero' particle detector at Fermilab in Batavia, Illinois, between 1998 and 2006. Towers herself worked as a postdoc on the project between 2000 and 2005. The findings of her survey were striking, she says. She claims that women did $40 \%$ more maintenance work than their male counterparts, and that female postdocs produced significantly more internal papers' per year. But based on that productivity they were only one-third as likely to be allocated conference talks as their male peers, she claims (http://arxiv.org/abs/0804.2026).

Conference presentations are critical to a young particle physicist's career. Papers from collaborations such as DZero have hundreds of authors in alphabetical order. Being given the chance to present results at a meeting is a major way for young researchers to stand out. "It's important," says Pauline Gagnon, a physicist with the ATLAS detector at CERN near Geneva,
Switzerland. "Being able to give talks is a way of rewarding individuals for their work."

Most particle detectors have internal committees that allocate conference presentations to researchers. These committees are frequently male-dominated, and Towers believes this lies behind the discrimination. "I don't think for a second that there is a conscious bias going on," she says. But the committees "are in danger of being prone to patronage and crony-

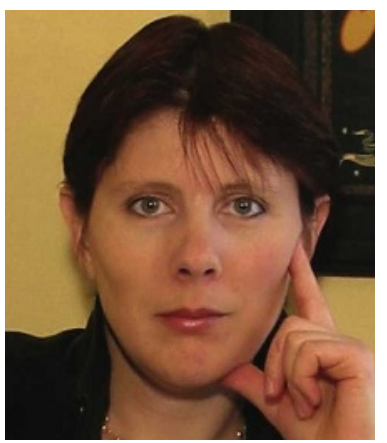

Sherry Towers assessed work data for an experiment at Fermilab. address the problem in its own speakers' committee.

After Towers complained, Fermilab launched an internal review in autumn 2006, says Bruce Chrisman, the lab's chief operating officer. An edited copy of the review obtained by Nature found that the collaboration "followed its policies correctly". But the investigator, a senior female physicist, added that complaints of gender discrimination in the group "should not ism". Male committee members are more likely to nominate male protégés to receive presentation time, she claims.

Some are sceptical of the findings. "I wasn't convinced that the effect she has found is real," says Kevin Pitts, a particle physicist at the University of Illinois at Urbana-Champaign. Internal papers are not necessarily a direct measure of productivity, he argues, and the small number of physicists surveyed is not enough to prove systematic bias. But Pitts is quick to add that he has little doubt that females do suffer gender discrimination: "In fact," he says, "I have personally observed this on more than one occasion."

Female physicists contacted by Nature said Towers's data matched their personal experiences of institutional sexism in physics. "You often see a young guy with an older guy gossiping and having coffee, but never a woman," says Freya Blekman, a physicist on the CMS experiment at CERN. "I'm convinced," agrees Gagnon. "There is absolutely no shadow of a doubt in my mind." She says the ATLAS collaboration is thinking about how to be summarily dismissed". There was a general feeling that females were being "passed over" for leadership roles, the report says.

DZero's leaders counter that bias, if it ever existed, is not plaguing the current collaboration. A survey of data between August 2006 and 2007 showed that women gave $17 \%$ of all talks despite making up just $12 \%$ of the collaboration, says DZero spokesman Dmitri Denisov.

Powers says the investigation didn't focus on postdocs and hasn't led to real changes at DZero. She wants the conference allocation system to be made more transparent and balanced. "The changes that need to be made are simple," she says. "It wouldn't cost them a dime."

And Towers says gender discrimination ultimately forced her out of particle physics. She adds that in 2004 her former employer, a prominent northeastern public university, tried to terminate her contract after she complained that she wasn't given adequate maternity leave. She has since filed a lawsuit against the university. $\mathbf{\square}$ Geoff Brumfiel

\section{Italian group claims to see dark matter - again}

Physicists in Italy claimed last week to have seen particles of dark matter. Their announcement has got their rivals riled and raises questions about what constitutes evidence of a new particle.

Rita Bernabei of the National Institute of Nuclear Physics in Rome presented her team's latest results on 16 April at an international meeting of particle physicists in Venice, Italy. Their detector, DAMA/LIBRA (Dark Matter Large Sodium lodide Bulk for Rare Processes), located deep under the country's Gran Sasso mountain, seems to be observing dark matter, Bernabei says.

Most agree that the experiment is picking up something: "They're seeing a signal, there's no doubt about that," says Tim Sumner of Imperial College London. But despite this, critics say that they don't believe the detector has found the elusive particles. "For me, it's not proof that they have seen dark matter," says Gilles Gerbier, a physicist at the Centre for Atomic Energy in Saclay, France. He adds that he's stumped by what's causing the signal.

Dark matter is believed by most physicists and astronomers to make up some $85 \%$ of the matter in the Universe. Most theories predict that it is some form of massive particle that interacts very rarely - if at all - with regular matter such as atoms. To date, most believe that dark matter has been spotted only indirectly via its pull on rotating galaxies and its effect on the shape of the early cosmos.

It's not the first time that Bernabei's team has made this claim. In 2000, they also claimed to have directly observed dark matter. The team uses ultrapure sodium iodide crystals, which theory predicts will give off flashes of light when they are struck by dark-matter particles. After several years of collecting data in the late 1990s, the group saw an increase in the number of flashes 